\title{
Inclusión Financiera para el Desarrollo del Cantón Quevedo 2018
}

\section{Financial Inclusion for the Development of Cantón Quevedo 2018}

*Lorena Silvana Vergara Suárez ${ }^{1}$ **Marisol Betty Véliz Aguilar², ***Mariasol Belén Culcay Véliz

${ }^{1}$ Adesor Consultoría, ${ }^{2}$ Universidad Técnica Estatal de Quevedo

*adesor.consultoria@gmail.com,*mveliz@uteq.edu.ec., ***mculcay@uteq.edu.ec.

Fecha de recepción: 13/03/2019

Fecha de aceptación: 15/06/2019

Publicado: 30/06/2019

\section{Resumen}

Desde la perspectiva de la investigación, el presente artículo tiene como objetivo contribuir al análisis de los mecanismos de inclusión financiera el Cantón Quevedo. Para ello se realizó una evaluación del estado del acceso y el uso de los servicios y productos financieros, así como de su calidad. Se realizó una síntesis del entorno de inclusión financiera mundial, regional y del Ecuador. Se ha definido el significado de inclusión financiera, y el marco normativo que rige al Sistema Financiero Nacional. Se desarrolló bajo el enfoque de investigación descriptiva, explicativa y cuantitativa, utilizando los recursos estadísticos publicados en las páginas web la Superintendencia de Economía Popular y Solidaria, Superintendencia de Bancos del Ecuador, Banco Central del Ecuador. Instituto Nacional de Estadísticas y Censos y la revisión de páginas web institucionales, de organismos de integración entre otros. Quevedo cuenta con presencia física de 18 entidades financieras y 204 canales de atención. Se cuantifican alrededor de 115.132 personas con productos crediticios, un total de 179.805 cuenta ahorristas y 160.584 clientes, el monto financiado alcanza USD 124,42 millones. El Sistema Financiero Nacional con presencia física en el cantón Quevedo ha contribuido notablemente con la inclusión financiera, dado que el 100\% del total de microempresarios y el $26 \%$ de la PEA se encuentra incluido financieramente. 
Palabras claves: Acceso y uso, Servicios Financieros, Inclusión financiera, Cantón Quevedo.

\begin{abstract}
From the perspective of research, this article aims to contribute to the analysis of financial inclusion mechanisms in Quevedo Canton. To this end, an assessment was made of the status of access and the use of financial services and products, as well as their quality. A synthesis of the global, regional and Ecuador financial inclusion environment was made. The meaning of financial inclusion has been defined, and the regulatory framework that governs the National Financial System. It was developed under the descriptive, explanatory and quantitative research approach, using the statistical resources published on the web pages by the Superintendence of Popular and Solidarity Economy, Superintendency of Banks of Ecuador, Central Bank of Ecuador. National Institute of Statistics and Census and the review of institutional web pages, of integration organisms among others. Quevedo has a physical presence of 18 financial entities and 204 service channels. About 115,132 people are quantified with credit products, a total of 179,805 account holders and 160,584 customers, the amount financed reaches USD 124.42 million. The National Financial System with a physical presence in the Quevedo canton has contributed significantly to financial inclusion, given that $100 \%$ of the total number of microentrepreneurs and $26 \%$ of the PEA is financially included.
\end{abstract}

Keywords: Access and use, Financial Services, Financial Inclusion, Canton Quevedo.

\title{
Introducción
}

\section{Entorno de Inclusión Financiera "IF"}

La inclusión Financiera es clave para reducir la pobreza e impulsar la prosperidad. Cifras del Banco Mundial de 2014 indican que Alrededor de 2500 millones de personas no utilizan servicios financieros formales y el $75 \%$ de los pobres no tiene cuenta bancaria. 
La inclusión financiera está en aumento a nivel mundial. La base de datos Global Findex ${ }^{1}$ de 2017 muestra que, a nivel mundial, el $69 \%$ de los adultos, 3.800 millones de personas, hoy tienen cuenta en un banco. Entre 2014 y 2017 abrieron cuentas 515 millones de adultos, si bien a nivel mundial hay 1700 millones de adultos que aún no están bancarizados, dos tercios de ellos poseen un teléfono celular que podría ayudarlos a acceder a los servicios financiero. No obstante, se muestra un gran avance en el acceso al financiamiento y grandes oportunidades para los responsables de formular las políticas y el sector privado para incrementar el uso y ampliar la inclusión entre las mujeres, los agricultores y los pobres. Esta tercera edición de la base de datos apunta a los avances en tecnología digital que son clave para lograr el objetivo del Banco Mundial de Acceso Financiero Universal para 2020.

En América Latina, donde los mayores de 15 años suman 454,7 millones, la proporción de adultos con al menos un servicio financiero es de 54,4\%. Además, mientras el 53,5\% tiene su

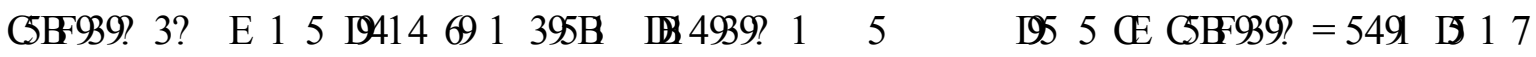
aplicativo móvil, destacó que el 41,9\% de los adultos que componen el $40 \%$ más pobre de América Latina y el Caribe tiene al menos un servicio financiero, mientras que el 52,6\% de los radicados en áreas rurales tiene una cuenta bancaria. la titularidad de cuentas entre los adultos en Ecuador aumentó del $37 \%$ en 2011 al $51 \%$ en 2017.

En Ecuador, la IF se constituye aún en un desafío, dado que no se cuenta con todas las facilidades que permitan la debida formalización de los servicios en términos financieros que incorpore a toda la población.

\footnotetext{
${ }^{1}$ La base de datos Global Findex, un amplio conjunto de datos sobre la manera en que las personas de 144 economías utilizan los servicios financieros, fue creada por el Banco Mundial con recursos de la Fundación Bill y Melinda Gates, y la colaboración de Gallup, Inc.
} 
El informe de Microscopio global $^{2}$ de 2018, indica que el entorno propicio para la inclusión financiera en Ecuador se ve debilitado por la falta de coordinación de alto nivel a través de una estrategia nacional de inclusión financiera. Los servicios financieros digitales y la innovación del dinero electrónico fueron sofocados por el esquema de dinero electrónico del Banco Central, pero en 2018 el sector comenzó a abrirse a instituciones financieras privadas. El sector popular y solidario, que atiende a la población de bajos y medianos ingresos, podría beneficiarse de un enfoque de supervisión basado en el riesgo. Los controles de la tasa de interés para los préstamos parecen limitar la disponibilidad de crédito entre la población de bajos ingresos.

Por su parte la Red de Instituciones Financieras de Desarrollo (RFD), ${ }^{3}$ realizó un estudio de IF, enfocado en el acceso y uso de servicios financieros de la población ecuatoriana. El estudio tuvo como objetivos identificar las necesidades financieras de la población en Ecuador (enfoque de demanda), evaluar el nivel de adecuación de los servicios financieros actualmente disponibles (enfoque de oferta) y determinar las posibles causas por las cuales una gran parte de la población del país aún no accede a servicios financieros. A partir de los resultados de esta medición se evidencia que en el país existen cerca de 4,2 millones de microempresarios, distribuidos en un 39\% en el área rural (1.541.407) y un 61\% en el área urbana (2.566.661). En términos de ahorro se estima que cerca de la mitad de los hogares ecuatorianos tienen una cuenta en una institución financiera, aunque el porcentaje de tenencia de cuenta es menor en el sector rural y en los estratos económicos más pobres de la población. En lo relacionado al crédito, en la encuesta de la CAF se evidencia que cerca de 2

\footnotetext{
${ }^{2}$ El Microscopio Global 2018 evalúa el entorno propicio para la inclusión financiera en 5 categorías y 55 países. La EIU rediseñó el marco de 2016 repensando los habilitadores claves de la inclusión financiera y agregando indicadores sobre servicios financieros digitales a cada dominio del marco.

${ }^{3}$ La Red de Instituciones Financiera de Desarrollo (RFD), al ser una entidad que agrupa a instituciones que velan por el sector de las microfinanzas y las finanzas populares y solidarias, en pro de una mayor inclusión financiera, tiene como misión principal ser un referente en este tema, a través de la generación de herramientas, iniciativas y políticas que permitan impulsarla.
} 
de cada 10 hogares ecuatorianos tienen un crédito en una institución financiera. Estos resultados van en línea con los de la Encuesta de Condiciones de Vida ECV del INEN, en el año 2014, en donde se afirma que el 17,6\% de los hogares ecuatorianos habían accedido a crédito entre el año 2013 y 2014.

En cuanto a los corresponsales no bancarios se observa que aún tienen una baja representación como un canal alternativo para realizar transacciones, ya que en la actualidad abarcan a cerca del $7 \%$ de las operaciones totales. En el documento se reconoce a la importancia del proyecto de dinero electrónico impulsado en primera instancia por el BCE y actualmente en una transición hacia los actores privados y de la Economía Popular y Solidaria (EPS). Se considera este como uno de los mecanismos con mayor potencial para generar mayor inclusión financiera (Polan F. 2017).

En este marco, el informe de IF de la subdirección de estadísticas y estudios de la SB, revela que el total de Incluidos Financieramente bordearía el 57,38\% de la Población Económicamente Activa Ocupada PEAO (7`712.178), esto es en torno a los 4,4 millones de personas. De los resultados a nivel nacional, se agruparon a diciembre de 2017, un número total de 799.270 clientes y 803.192 cuentas, conforme a la información estadística remitida por la banca privada controlada por la SB, mostraba un total de 29.801 puntos de atención, de los cuales el $82,44 \%$ constituyen los corresponsales no bancarios CNB, un 13,23\% los cajeros automáticos, un 2,96\% las agencias bancarias y apenas el 1,38\% los demás servicios de la banca. A la fecha de análisis, tres entidades concentraron el 92,35\% del total de puntos de atención. Guayaquil (18,80\%), Pichincha (34,98\%) y Pacífico (38,57\%) (Tovar P. 2017).

En este marco, el Banco Central del Ecuador (BCE) en cumplimiento de los mandatos constitucionales viene aplicando una política pública de inclusión financiera, a fin de ampliar a través del Sistema Nacional de Pagos, el acceso y utilización de los servicios financieros a segmentos de la población con limitado acceso a estos servicios. Por ejemplo dentro de la 
$=99 \quad 45 \quad 50145$ Promover la participación de las entidades que conforman el Sistema Financiero Nacional en el Sistema Nacional de Pagos y fomentar la inclusión financiera mediante el acceso a servicios financieros formales a segmentos de la población excluidos o con limitado acceso a ellos .

\section{Consideraciones teóricas sobre el concepto de inclusión financiera (IF)}

Inclusión Financiera IF: Estas dos palabras de uso creciente en el mundo de la academia, de la teoría económica y de las políticas públicas, a pesar de que gramaticalmente unidas no alcanzan para construir una oración, constituyen sin embargo una potente idea-fuerza que conquista cada vez más espacios y se instala dentro de las agendas de los grandes, medianos y pequeños actores -públicos y privados; económicos y políticos- de nuestras sociedades. (Ramos, 2018, p.10.)

Definición: Según el Banco Mundial, la IF puede definirse como el acceso que tienen los agentes económicos (personas, familias, empresas) a una gama de productos y servicios financieros útiles y asequibles que satisfacen sus necesidades, como transferencias, pagos, crédito, ahorro, seguros, etc. formales y de calidad; así como también de su uso bajo un marco de estabilidad financiera para el sistema y los usuarios.

Acceso: Es la dimensión que hace referencia a la existencia de puntos de atención e infraestructura, tomando en cuenta la penetración geográfica de los mismos y una oferta de servicios de calidad que se encuentra al alcance de la población.

Uso: Se refiere a la adquisición o contratación, por parte de la población, de uno o más productos o servicios financieros sean digitales o no, así como a la regularidad y frecuencia de uso estos medios para realizar operaciones financieras.

Calidad: Se refiere a la existencia de productos y servicios financieros que se ajustan a las necesidades de la población. Asimismo, a la eficiencia que tiene la tecnología digital de evitar los riesgos de interrupción de servicios y del extravío de datos, incluida las instrucciones de 
pago, así como el riesgo de que una transmisión digital y el almacenamiento de datos generen una violación de la privacidad o de la seguridad.

La Red de Instituciones Financiera de Desarrollo (RFD) $81456994 ? 1 \quad 3 ?=? \quad 335$ C $?$ y uso de servicios financieros formales bajo una regulación apropiada que garantice esquemas de protección al usuario financiero y promueva la educación financiera para mejorar las capacidades de to4?C ?C657=5 DC45 1 @2 2139

Para Urgiles $\mathrm{J}^{4}$, la inclusión financiera no es solamente un ejercicio financiero, es una acción en diferentes espacios, entendida como la construcción de una sociedad más cooperante, solidaria, recíproca, consciente de esos principios. Es una herramienta para abrir espacios, que den como resultado, una serie de sujetos que tienen beneficios por vivir y, una de las herramientas para poder garantizar esa reciprocidad es la inclusión financiera.

En el presente análisis sobre 1 3 EG 691 395B $\quad$ C5 814569 94? 3?=? 5 mecanismo que hace posible el uso cotidiano de los productos y servicios financieros con el fin de facilitar la transaccionalidad financiera por parte de la población y el mejoramiento en la canalización y el uso de sus recursos económicos.

\section{EI Sistema Financiero del Ecuador}

Desde el 2008, la Constitución de la República del Ecuador, en el artículo 283 define al QCAs=1 53? =93? 3?=? C?39 I C 941B? AE5 B33? ?35 1 C5B8E=1 ? 3?=? (E 5D I 69 que propende a una relación dinámica y equilibrada entre sociedad, Estado y mercado, en armonía con la naturaleza; y que tiene por objetivo garantizar la producción y reproducción

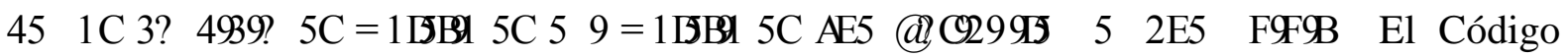

\footnotetext{
${ }^{4}$ Juan Caslos Urgiles, Tiene trayectoria profesional de más de 20 años en el Sector Microfinanciero. Consultor y expositor nacional e internacional. Actualmente es Gerente General de la Cooperativa Jardín Azuayo.
} 
Orgánico monetario y financiero (COMF, 2014) $)^{5}$ en su Art. 160 dispone que el sistema financiero nacional se compone de los sectores público, privado y del popular y solidario, que intermedian recursos del público y prescribe que cada uno de estos sectores contará con normas y entidades de control específicas y diferenciadas, que se encargarán de preservar su seguridad, estabilidad, transparencia y solidez.

\section{Marco regulatorio de los Productos y Servicios Financieros en el Ecuador}

Tasas de interés del Banco Central del Ecuador: ${ }^{6}$, La Junta de Política y Regulación Monetaria y Financiera determinará las tasas de interés aplicables a las operaciones activas y pasivas del Banco Central del Ecuador y las tarifas que el Banco cobrará por sus servicios (COMF. Art. 131), el 26 de enero de 2018 emitió la resolución No. 437-2018-F a través de la cual fijó las tasas de interés activas efectivas máximas para el microcrédito, aplican para el sector financiero público, el sector financiero privado, las mutualistas y entidades del segmento 1 del SFPS. Para las demás entidades, se mantendrán las establecidas en la resolución 044-2015-F del 05 de marzo del 2015, Normas que regulan la fijación de las Tasas de Interés Activas Efectivas Máximas .

En lo Concerniente a la Cartera de créditos, la JPMF mediante Resolución No. 043-201SF, aprobó las "Normas que regulan la Segmentación de la Cartera de Crédito de las Entidades del Sistema Financiero Nacional

\footnotetext{
${ }^{5}$ (COMF 2014) Artículo 1.- Objeto. El Código Orgánico Monetario y Financiero tiene por objeto regular los sistemas monetario y financiero, así como los regímenes de valores y seguros del Ecuador. Artículo 2.- Ámbito. Este Código establece el marco de políticas, regulaciones, supervisión, control y rendición de cuentas que rigen los sistemas monetarios y financiero, así como los regímenes de valores y seguros, el ejercicio de sus actividades y la relación con sus usuarios.

6 El Banco Central del Ecuador tiene por finalidad la instrumentación de las políticas monetaria, crediticia, cambiaria y financiera del Estado, mediante el uso de los instrumentos determinados en este Código y la ley. (COMF Art. 27)
} 
En cuanto a Servicios Financieros, para el Sector Financiero Popular y Solidario mediante Resolución No. 165-2015-F 5= 95 1 Norma de Servicios Financieros de las Entidades del Sector Financiero Popular y Solidario I @B 5 Sector Financiero Público y Privado mediante Resolución No. 138-2015-F 5H@945 1 Norma de Servicios Financieros de las Entidades del Sector Financiero Público y Privado

\section{Metodología}

El sistema financiero nacional para fomentar el acceso a servicios financieros tiene los Instrumentos de IF que se observan en la siguiente tabla (Tovar P. 2017 p.7).

Tabla 1.

Metodología de Inclusión Financiera en el Sistema Financiero Nacional

\begin{tabular}{|c|c|c|c|}
\hline $\begin{array}{l}\text { Instrumentos } \\
\text { de Activo }\end{array}$ & Créditos & Uso de mecanismos de Crédito & $\begin{array}{l}\text { Créditos: } \\
\text { Por Líneas de Crédito }\end{array}$ \\
\hline $\begin{array}{l}\text { Instrumentos } \\
\text { del Pasivo }\end{array}$ & Depósitos & $\begin{array}{l}\text { Uso de mecanismos de ahorro } \\
\text { (administración de los } \\
\text { Ingresos) }\end{array}$ & $\begin{array}{l}\text { Cuenta Básica } \\
\text { Cuenta Depósitos } \\
\text { Monetarios } \\
\text { Cuenta Depósitos de } \\
\text { Ahorro }\end{array}$ \\
\hline $\begin{array}{l}\text { Productos y } \\
\text { Servicios }\end{array}$ & $\begin{array}{l}\text { Uso de Productos } \\
\text { y Servicios } \\
\text { Financieros }\end{array}$ & $\begin{array}{l}\text { Uso de los puntos de atención } \\
\text { físicos que permiten hacer } \\
\text { transacciones financieras. }\end{array}$ & $\begin{array}{l}\text { Puntos de Atención como: } \\
\text { Matrices, } \\
\text { agencias, } \\
\text { automáticos, } \\
\text { corresponsales } \\
\begin{array}{ll}\text { bancarios, entre otros. } \\
\text {. no }\end{array}\end{array}$ \\
\hline
\end{tabular}

Fuente: SB-INRE-DEGI-SEE. Elaboración: Autoras

En este sentido el presente artículo se desarrolló bajo el enfoque de investigación descriptiva, explicativa y cuantitativa, para determinar el uso de los mecanismos de crédito, se consideró la información estadística disponible en estudios del Banco Central del Ecuador (BCE), reportes de colocación, boletines financieros e informes gerenciales publicados por la Superintendencia de Bancos (SB) y la Superintendencia de Economía Popular y Solidaria (SEPS), para intentar cuantificar el uso de mecanismos de ahorro se consultaron los reportes de captaciones y estudios publicados por el BCE, la SB y la SEPS. Y para determinar uso de 
los puntos de atención físicos que permiten hacer transacciones financieras hizo una revisión de páginas web institucionales.

Para revelar los índices en que contribuyen los instrumentos de inclusión financiera que aplican las instituciones financieras (IFIS) en el Cantón Quevedo, se establecen los siguientes EdE5C) 45 Inclusión Financiera:

\begin{tabular}{|c|c|}
\hline $\mathbf{T}=\mathbf{C} 1 / \mathbf{C}_{0}$ & $(\%$ DE TENDENCIA $=$ Cifra Comparada $/$ Cifra Base $)$ \\
\hline $\mathbf{T}=\mathbf{C} 1 / \mathbf{N}$ & $(\%$ PROMEDIO $=$ Cifra Comparada $/$ Numero de Entidades $)$ \\
\hline IF1 = TCT / PEA & $\begin{array}{l}\text { (\% INCLUSIÓN FINANCIERA A CUENTA AHORRISTAS } \\
\text { Total Cuentas / población Económicamente Activa }\end{array}$ \\
\hline $\mathrm{IF}_{2}=\mathrm{TCL} / \mathrm{PEA}$ & $\begin{array}{l}\text { (\% INCLUSIÓN FINANCIERA A CLIENTES }=\text { Total Clientes / } \\
\text { Población Económicamente Activa }\end{array}$ \\
\hline $\mathbf{I F M}=\mathbf{T M C} / \mathbf{T M}$ & $\begin{array}{l}\text { (\% CAPITALIZACIÓN MICROFINANCIERA }=\text { Total } \\
\text { Microempresas Capitalizadas / población Económicamente Activa }\end{array}$ \\
\hline $\mathrm{IFE}=\mathrm{TMC} / \mathrm{P}$ & $\begin{array}{l}\text { (\% INCLUSIÓN FINANCIERA A EMRENDIMIENTOS }=\text { Total } \\
\text { Microempresas Capitalizadas / población Económicamente Activa }\end{array}$ \\
\hline
\end{tabular}

Según la información (SNI-INEC:2010), El cantón Quevedo cuenta con 173.575 habitantes, la población económicamente activa asciende a 68.367, y 63.440 personas pertenecen a la población económicamente activa Ocupada. Por otro lado, según datos (SRI-2016) citados por Purcachi, W., Pérez M. y Arguello L. (2017) indican que el número total de empresas asciende a 9.549 y el $96 \%$ está concentrado por microempresas, alcanzando la cifra de 9.167 microempresas en el Cantón Quevedo.

\section{Resultados}

\section{Colocaciones por tipo de Crédito}

La inclusión financiera en América Latina como Región y en Ecuador en particular, está fuertemente vinculada con la facilidad que prestan las instituciones financieras a la hora de instrumentar operaciones crediticias, ligado sin duda al costo del crédito en relación con el 
riesgo. El cantón Quevedo de la provincia de los Ríos cuenta con la presencia física de dieciocho (18) entidades que realizan actividades de intermediación financiera, tanto del Sector Financiero Popular y Solidario (SFPS), de la Banca Pública (BPU) y de la Banca Privada (BP).

Uno de los principales mecanismos de inclusión financiera del Sistema Financiero Nacional, se deriva de la variable colocaciones, como se observa en la figura1, Las siete entidades del SFPS constituye el 54\% del total de colocaciones en el SFN local, seguido del aporte de los once bancos que corresponden a la BP con el 38\%, y el $8 \%$ lo representa la BPU es decir BanEcuador.

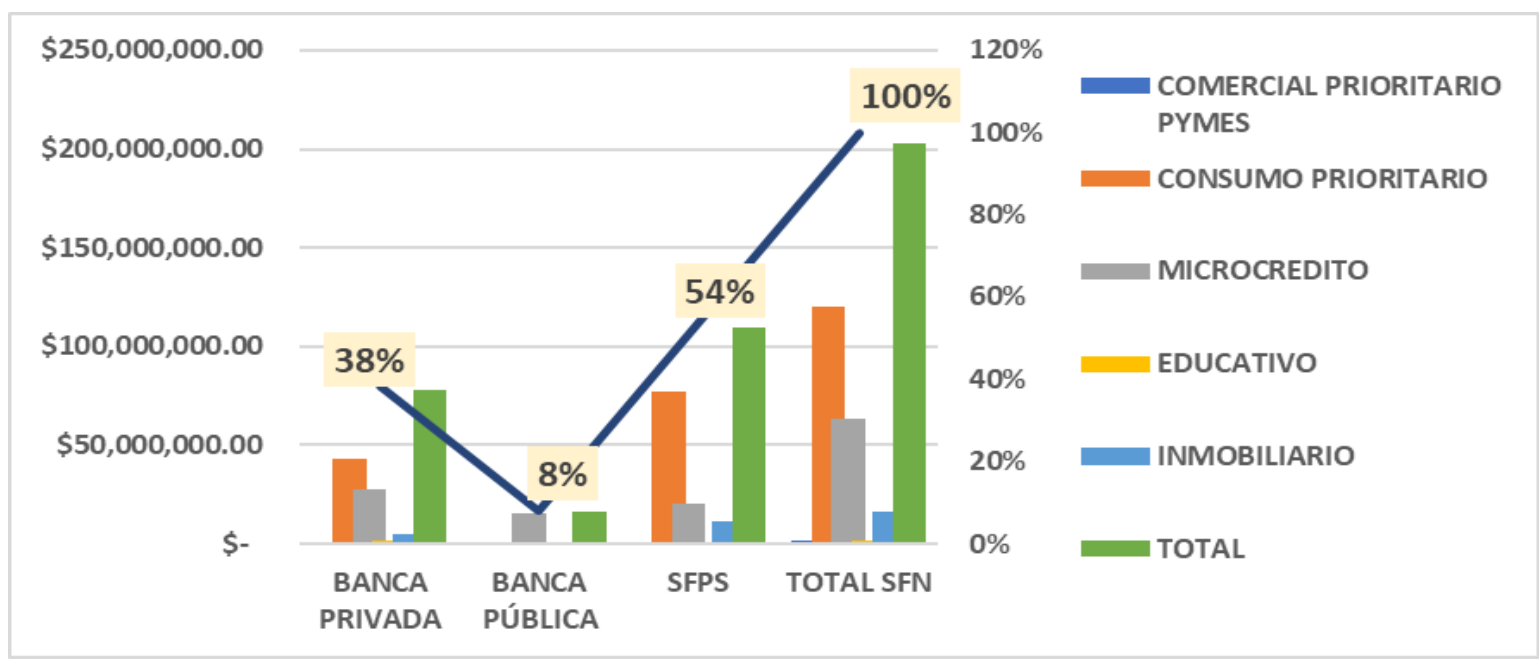

Figura 1. Porcentaje de Participación en la variable colocación de las Entidades financieras con Presencia física en el cantón Quevedo. Dirección Nacional Técnica y Estadística. Reportes de colocaciones. DIEE-SFPS-SEP. Elaboración: Autoras

De conformidad a la información obtenida mediante reportes de colocaciones de los organismos de control, a diciembre del 2018, la cifra total de colocaciones asciende a USD 208,70 millones, de los cuales 109.67 millones aportó el SFPS, USD 83,16 millones alcanza la Banca Privada y USD 15.86 BanEcuador. (Gráfico 2).

El crédito de consumo prioritario es el mas demandado en el SFN del cantón Quevedo, por ende el producto que aportó 59\% participación de la colocación total con USD 124,42 millones, de los cuales el 56\% fue colocado por la Cooperativa de Ahorro y Crédito de la 
Policía nacional cifra que asciende a USD 69.62 millones (Anexo 1), por su parte el Banco Pichincha y Banco Guayaquil colocaron USD 18.68 millones y USD 11.61 millones respectivamente, alcanzando el $24 \%$ de participación. (Anexo 2).

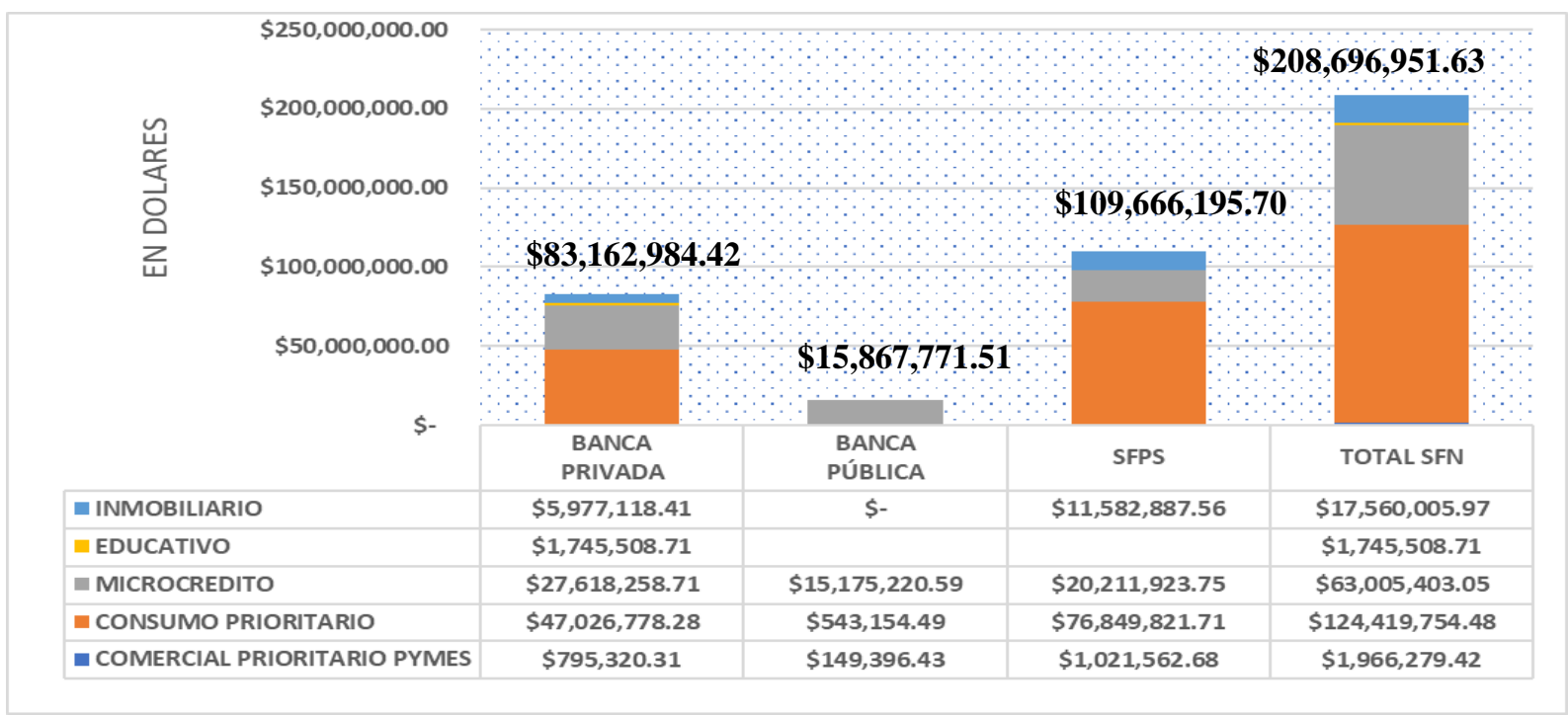

Figura 2. Volumen del Monto de la Cartera Bruta por tipo de crédito de las Entidades Financieras con Presencia física en el cantón Quevedo. A diciembre 2018 (SFPS). A noviembre 2018 (BP-BPU). Reportes de colocaciones. DIEE-SFPS-SEPS y Distribución Geográfica de la Serie de Colocaciones. BP-BPU-SB. Elaboración: Autoras

Inclusión Financiera es el término evolucionado e internacionalmente aceptado de su génesis el microcrédito, las microfinanzas y las microfinanzas inclusivas. Es también el resultado evolutivo, a la fecha, que recopila las experiencias y lecciones aprendidas a nivel mundial e introduce un concepto mucho más integral en lo relacionado a la provisión de productos y servicios financieros no solo para la población de bajos ingresos, en su mayoría, propietaria de micro, pequeños y medianos negocios, informales en su mayoría, sino como un derecho de la población en general, para acceder y relacionarse con las instituciones que conforman los sistemas financieros de los países.

En este sentido las entidades financieras, han apostado a una creciente inclusión microfinanciera, en el cantón Quevedo 17 entidades otorgan microcrédito, se exceptúan la mutualista pichincha y el Banco Bolivariano, al aporte de este producto crediticio se suma la Cooperativa Juventud Progresista Ecuatoriana (JEP), pese a no contar con presencia local. En 
este producto se ha colocado USD 63 millones, Banecuador a noviembre del 2018 aportó con el 24\% de colocación USD 15.18 millones, abe precisar que el 96\% de las colocaciones de esta entidad corresponden al segmento microempresa, seguido de la Cooperativa de Ahorro y Crédito de la Pequeña Empresa del Cotopaxi (CACPECO), con USD 12 millones (19\%), Banco Pichincha USD 6.9 millones (19\%), Banco Solidario USD 5.7 millones (9\%) y Finalmente Banco Finca USD 5.2millones (8\%). (anexo2)

Por otro lado, el SFN local entregó USD 17.56 en créditos inmobiliarios, el SFPS colocó USD 11.58 millones, la Mutualista Pichincha concentró el $51 \%$ de la colocación alcanzando la cifra de UDS 8,87 millones, seguido de la COAC Policía Nacional con USD 2.5 millones (14\%) y el Banco Pacífico con USD 1.7 millones (10\%). (Anexo 2).

El aporte en crédito Educativo alcanza USD 1.7 millones, el 99\% de este rubro fue otorgado por el Banco del Pacifico y la diferencia por el Banco Guayaquil. Finalmente, la cifra entregada en crédito comercial prioritario Pymes alcanza USD 1.97 millones, en este producto se destaca la COAC CACPECO con el 32\% de participación y USD 392 mil. (Anexo 2).

\section{Volumen del número de operaciones por tipo de crédito}

Según datos proporcionados en el informe de Evolución de las Operaciones Activas y Pasivas del Sistema Financiero Nacional del Banco Central del Ecuador (BCE), ${ }^{7}$ a febrero de 2018, los montos promedios por productos de crédito son los siguientes, Comercial (3.394), Consumo (1.274), Microempresarial (3.872.6), Educativo (10801.12), Vivienda (53.632.9). En este contexto a diciembre del 2018 se alcanza una cifra de 115.132 personas IF con

\footnotetext{
${ }^{7}$ Se calculó el número de operaciones relacionando el monto de cartera colocada para el monto promedio de crédito, ultimo disponible a la fecha de elaboración de la investigación: Evolución de las Operaciones Activas y Pasivas del Sistema Financiero Nacional del BCE, a febrero de 2018., Comercial (3.394), Consumo (1.274), Microempresarial (3.872.6), Educativo (10801.12), Vivienda (53632.9).
} 
productos crediticios. A razón de que el $154 \%$ de la PEA se encuentra incluida financieramente con créditos de consumo, se presume que el 100\% de la población que recibe ingresos ya sea por remuneración o ganancias tiene un crédito de consumo y un 54\% de dicha población mantiene crédito se consumo en dos entidades del SFN local. El 177\% del total de microempresarios se encuentra incluidos microfinnacieramente, presumiblemente cada microempresario mantiene dos operaciones crediticias en distintas entidades del SFN local. Con relación a la PEA el 24\% estarían IF y el 26\% de la PEAO. (Figura 3, anexos 3 y 4).

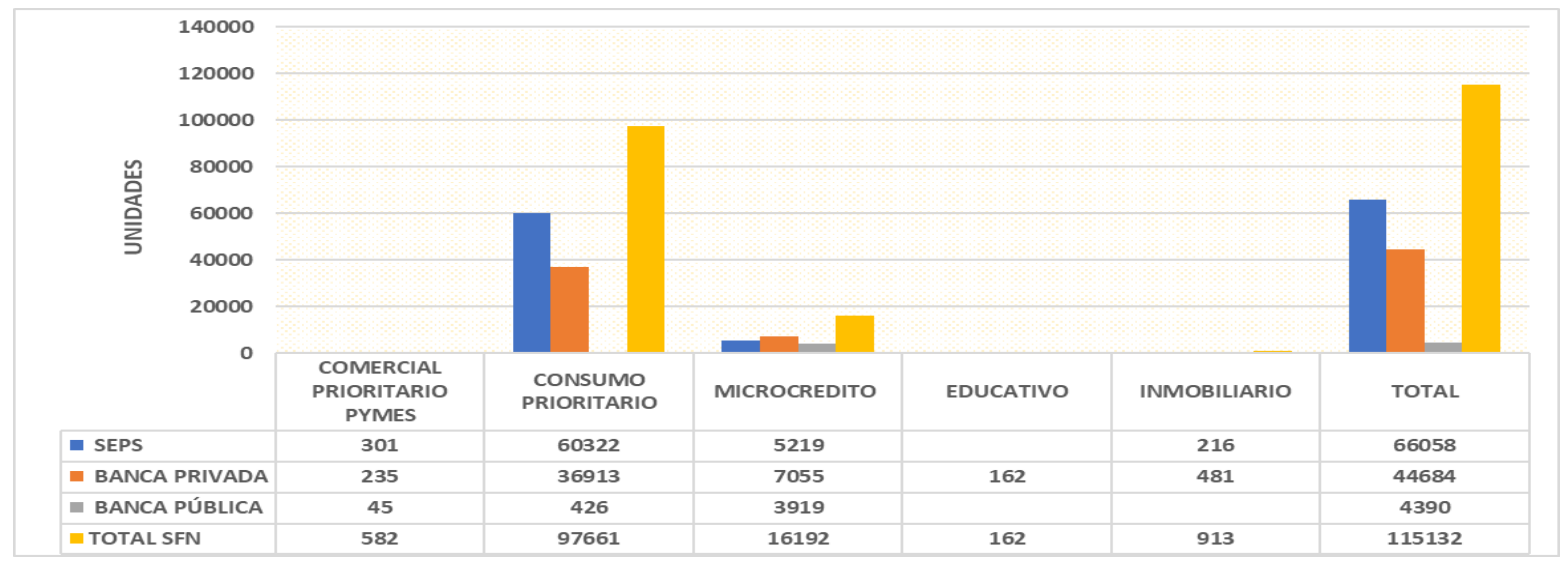

Figura 3. Volumen del número de operaciones por tipo de crédito del Sistema Financiero Nacional con presencia en el Cantón Quevedo, A diciembre 2018 (SFPS). A noviembre 2018 (BP-BPU) en unidades. Dirección Nacional de Síntesis Macroeconómica (BCE. Elaboración: Autoras

\subsection{Captaciones de Ahorro}

A diciembre de 2018, la demanda de servicios financieros formales en el cantón Quevedo en lo que se relaciona con los depósitos ${ }^{8}$ financieros se cuantificó en USD 180.64 millones se estructuró de la siguiente forma: los depósitos a la vista cuantificaron USD 123.91 (64\%) millones, mientras que los depósitos a plazo totalizaron USD 52.50 millones (34\%), los depósitos restringidos sumaron la cifra de USD 5.23 millones (3\%) ver gráfico 4. El SFPS aportó con el $56 \%$ en los Depósitos a plazo y el $42 \%$ depósitos a la vista, lo contrario de la

\footnotetext{
$8 / 5 \quad$ 1D ?7? $\quad 93 ? 45 \quad$ E5 IDC $\quad \% \quad$ AE5 = 1 I95 $51 \quad$ Depósitos a la vista De que son exigibles mediante la presentación de una libreta de ahorro. los depósitos a plazo exigibles al vencimiento de un período no menor a 30 días (contrato de intermediación financiera. Depósitos Restringidos: - Registra el valor de los depósitos que por disposición legal o por acuerdo privado tengan la característica de no tener una libre disponibilidad, ni de poder ser retirados en cualquier tiempo, como por ejemplo los valores recibidos para constituir cuentas de integración de capital y los depósitos que garantizan operaciones de crédito, entre otros.
} 
BP que tiene mayor concentración depósitos en ahorros al avista 69\% y 29\%. El margen de intermediación financiera que realiza el SFN local, alcanza una cifra porcentual del 88\%, mientras que la BP alcanza el 46\%, el SFPS. (Anexo 5)

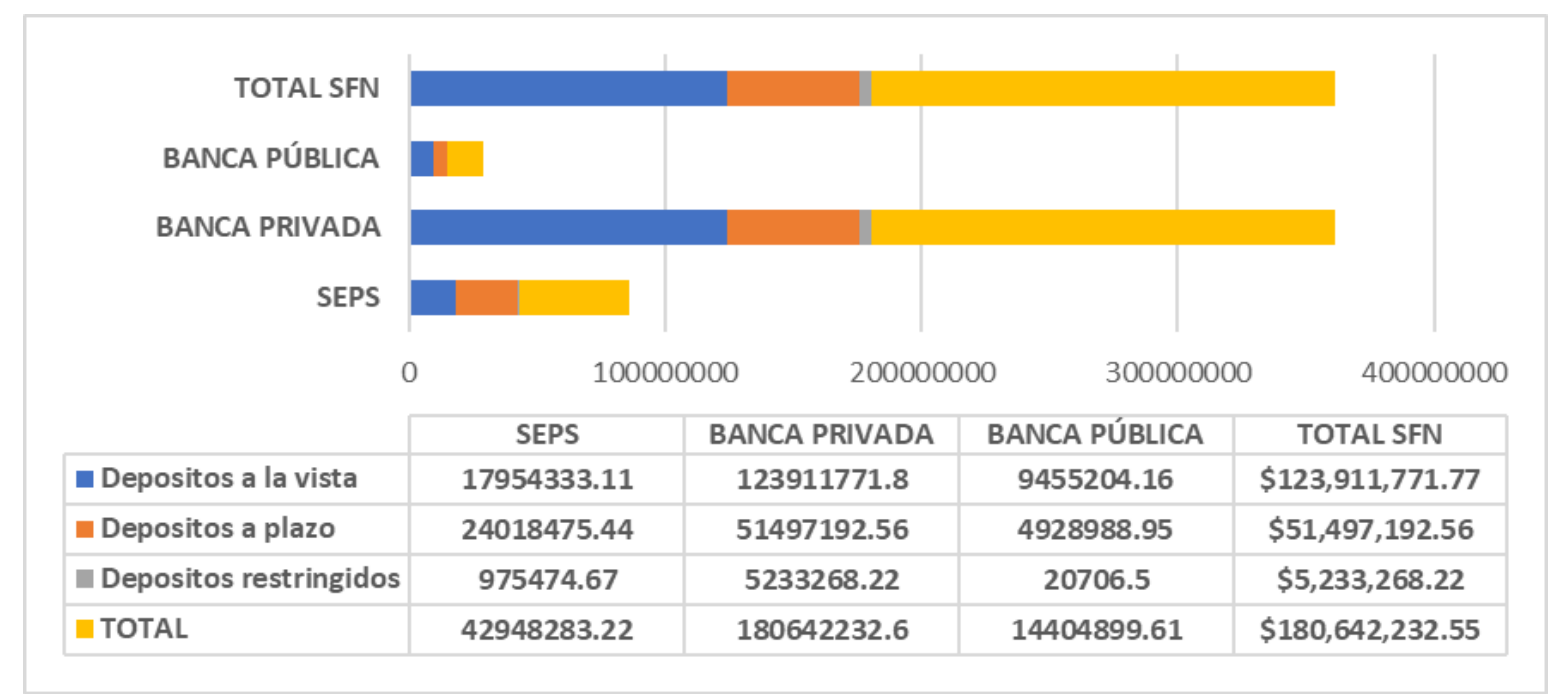

Figura 4. Volumen de Captaciones del Sistema Financiero Nacional con presencia en el Cantón Quevedo, a diciembre 2018 (SFPS). A noviembre 2018 (BP-BPU) en dólares. Reportes de captaciones. DIEE-SFPS-SEPS y Distribución Geográfica de la Serie de captaciones. BP-BPU-SB. Elaboración: Autoras

\section{Numero de Cuentas y Clientes}

Por otra parte, y con base en la información recuperada de las publicaciones disponibles en las web institucionales de los organismos de control, se estableció el número de clientes y cuentas que se maneja en el SFN observándose que hay un total de 179.805 cuentas y 160.584 clientes registrados oficialmente en el SFN local. (Grafico 5 y Anexo 5)

En tal virtud, la presente investigación presume que, las cuentas del SFN local alcanzan el $261 \%$ de la PEA y los clientes representan el 234\% de la PEA. Comprobándose que la PEA tiene cuenta en tres entidades financieras y son clientes en dos entidades financieras. 


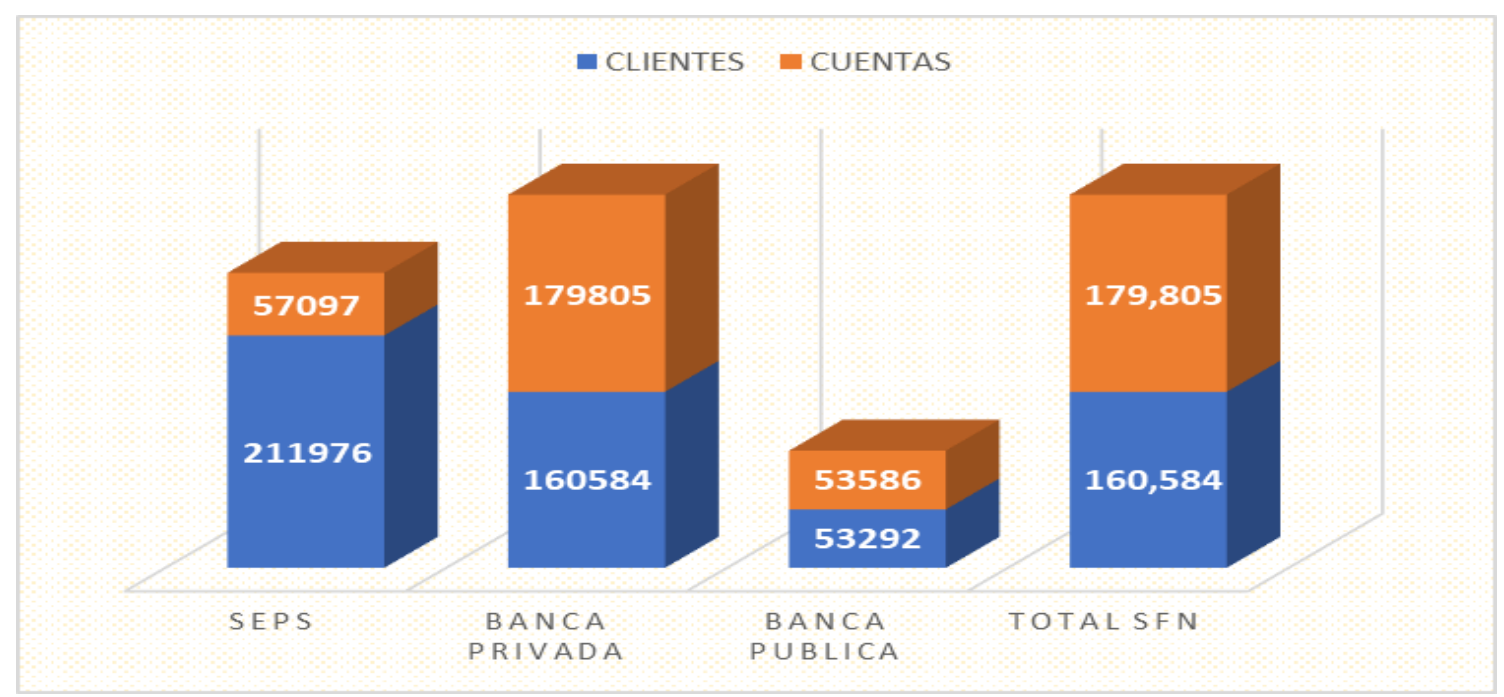

Figura 5. Numero de Cuentas y Clientes del Sistema Financiero Nacional con presencia en el Cantón Quevedo, A diciembre 2018 (SFPS). A noviembre 2018 (BP-BPU) en unidades. Reportes de captaciones. DIEE-SFPSSEPS y Distribución Geográfica de la Serie de captaciones. BP-BPU-SB. Elaboración: Autoras

\section{Monto Promedio en Cuenta de Ahorros}

La disponibilidad de recursos aunque estos sean limitados, posibilita el acceso a los servicios financieros, y permite la apertura de cuentas de ahorro, facilitándose a los usuarios de segmentos deprimidos financieramente, la introducción de la cultura financiera y de ahorro que más tarde se convertirá en conceptos de transaccionalidad financiera de un segmento informal al formal.

Dada la información estadistica utilizada en el presente estudio, se determina que el monto promedio de ahorro del SFN local, asciende a USD 428.20 (gradico 6). Siendo el mas alto el de la banca privada cuyo monto promedio de ahorros alcanza USD 818.21 (grafico 6). La entidades con promedios mas altos de ahorros son Banco Bolivariano USD \$1,669.56, seguido de Banco de Machala con la cifra de USD \$1,607.55 y Banco Internacional con USD \$1,348.75. Así mismo los montos promedios minimos en ahorro USD \$29.23 por la COAC Juan Pio de Mora, USD \$33.95 y USD \$42.89 Banco D-Miro. (Anexo 5) 


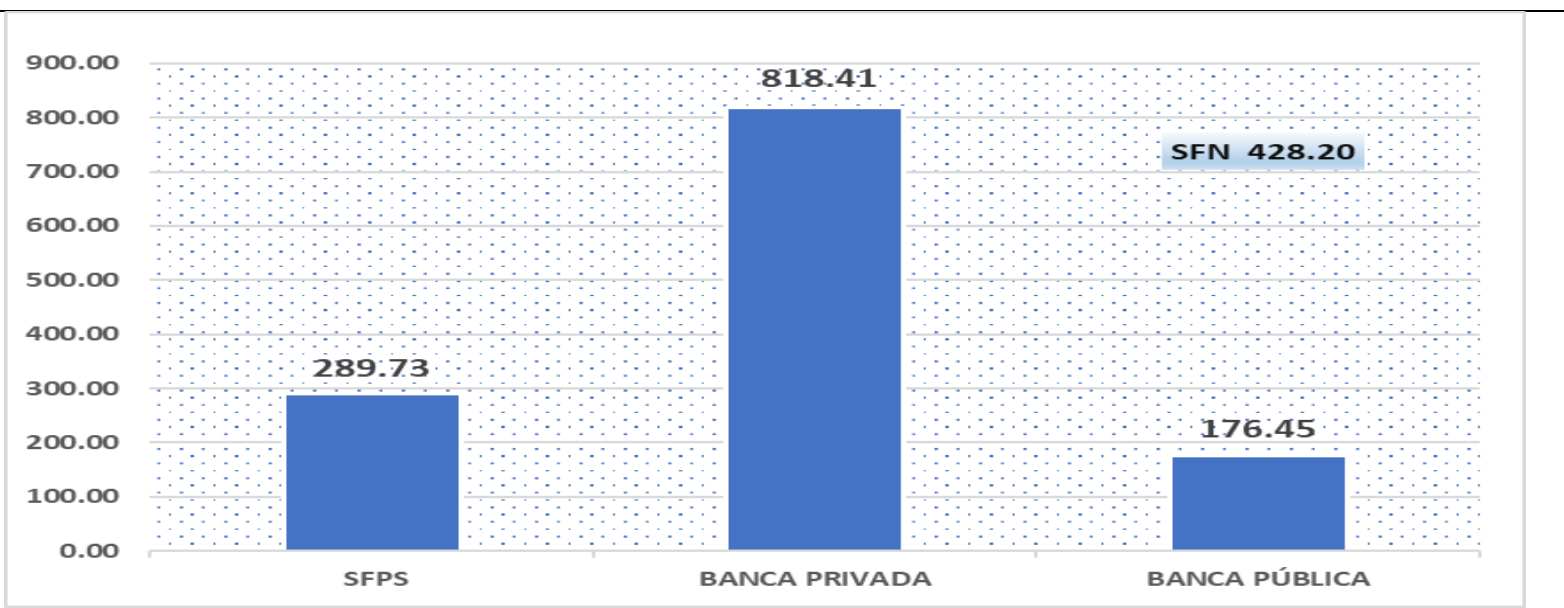

Figura 6. Monto promedio en cuentas del Sistema Financiero Nacional con presencia en el Cantón Quevedo, en valores absolutos. Reportes de captaciones. DIEE-SFPS-SEPS y Distribución Geográfica de la Serie de captaciones. BP-BPU-SB. Elaboración: Autoras

\section{Canales de Atención}

Si bien, el poder brindar un mayor y mejor acceso a los servicios financieros constituye un desafío para el SFN, particularmente en las IFIS del cantón Quevedo, en los últimos años se ha visto una mayor y mejor cobertura en lo relativo a puntos de atención? razón que contribuyen notablemente a la inclusión financiera, al disponer un total de 204 canales de atención (tabla 2), 3 sucursales, 20 agencias, 37 cajeros automáticos, 4 cajeros con transaccionalidad de depósitos y 139 corresponsales no bancarios (CNB) de estos 96 corresponden a Pichincha mi Vecino de Banco Pichincha, 33 bancos del Barrio del Banco Guayaquil, por el lado de Banco Pacifico (Mi Banco Banco Aquí) y Banco Bolivariano, 5 cada uno. Se presume que en el cantón Quevedo por cada 335 personas de la POA existe un canal de atención e inclusión financiera.

\footnotetext{
${ }^{9}$ SUC: Sucursal, AG: Agencia, VE: Ventanilla de Extensión, ATM1: Cajeros automáticos, ATM2: Cajeros automáticos que adicionalmente aceptan depósitos, CNB: Corresponsales no Bancarios) Puntos de atención donde reciben depósitos, retiros y pagos de servicios.
} 
Tabla 2.

Canales de Atención del Sistema Financiero Nacional con presencia en el Cantón Quevedo, A diciembre 2018. Unidades

\begin{tabular}{|c|c|c|c|c|c|c|c|}
\hline IFIS & SUC & AG & VE & ATM1 & ATM2 & CNB & T. CA \\
\hline BANCO PICHINCHA C.A. & 1 & 3 & & 11 & 3 & 96 & 114 \\
\hline COAC JEP & & & & 5 & & & 5 \\
\hline BANCO DEL PACIFICO S.A. & & 2 & & 4 & & 5 & 11 \\
\hline BANCO GUAYAQUIL S.A. & & 2 & & 4 & 1 & 33 & 40 \\
\hline BANCO BOLIVARIANO C.A. & & 1 & & 3 & & 5 & 9 \\
\hline BANCO INTERNACIONAL S.A. & & 1 & & 2 & & & 3 \\
\hline BANCO DE MACHALA S.A. & 1 & & & 2 & & & 3 \\
\hline BANCO DE LA PRODUCCION S.A. & 1 & & 1 & 1 & & & 3 \\
\hline BANECUADOR & & 1 & & 1 & & & 2 \\
\hline COAC 29 DE OCTUBRE & & 1 & & 1 & & & 2 \\
\hline COAC CACPECO & & 1 & & 1 & & & 2 \\
\hline COAC POLICIA NACIONAL & & 1 & & 1 & & & 2 \\
\hline MUTUALISTA PICHINCHA & & 1 & & 1 & & & 2 \\
\hline BANCO D-MIRO S.A. & & 1 & & & & & 1 \\
\hline BANCO FINCA S.A. & & 1 & & & & & 1 \\
\hline BANCO SOLIDARIO & & 1 & & & & & 1 \\
\hline BANCO VISION FONG & & 1 & & & & & 1 \\
\hline COAC JUAN PIO DE MORA & & 1 & & & & & 1 \\
\hline COAC SAN ANTONIO & & 1 & & & & & 1 \\
\hline TOTAL IFIS & $\mathbf{3}$ & 20 & 1 & 37 & 4 & 139 & 204 \\
\hline
\end{tabular}

Fuente: GC-Banco Pichincha ${ }^{10}$ y páginas web institucionales de las IFIS. Elaboración: Autoras

\section{Conclusión}

La condición de inclusión financiera

de una población, derivada de una remuneración monetaria por empleo o pago de cualquier índole, es un mecanismo considerablemente significativo en pro del desarrollo económico del cantón y de sus familias. Este hecho, no solo permite la dinamización de estos agentes económicos en torno al ahorro y al crédito, sino que plasma mediante el uso y acceso de los servicios y productos financieros, la canalización formal de los recursos financieros y todo lo que ello conlleva. En la elaboración del presente artículo y, mediante la realización de los respectivos cálculos, se establece que $168 \%$ con relación a la PEA (68.367 personas) estarían incluidos financieramente, esto entorno a los 115.132 beneficiarios de productos crediticios. Las cuentas del SFN local alcanzan el $261 \%$ de la PEA y los clientes representan el $234 \%$ de la PEA. Con estos resultados, se puede inferir que, con base en los ingresos monetarios percibidos, la PEA de Quevedo mantendría una cuenta de ahorros en aproximadamente tres entidades financieras locales, y estarían en capacidad de retirar dinero o ahorrar; es decir, esto les permite la utilización de los productos

\footnotetext{
${ }^{10}$ Ing. Manuel Cerda Molestina, MSc. Gerente Comercial de Banco Pichincha Sucursal Quevedo.
} 
o servicios financieros; $y$, por ello con seguridad serían parte de la población incluida financieramente.

\section{Referencias bibliográficas}

Banco Central del Ecuador, (2018). Evolución de las Operaciones Activas y Pasivas del Sistema Financiero Nacional, Subgerencia de Programación y Regulación, Dirección Nacional de Síntesis Macroeconómica, Quito, febrero 2018 https://contenido.bce.fin.ec/documentos/Estadisticas/SectorMonFin/BoletinTasasInteres/ec t201802.pdf

Banco Mundial, (10 de septiembre de 2014). World bank Group. Recuperado el 15 de octubre de 2018, de www.cgap.org: https://www.cgap.org/sites/default/files/Focus-NoteAMLCFT-and-Financial-Inclusion-Sept-2014-Spanish.pdf.

Código Orgánico Monetario y Financiero, COMF (2014). Registro oficial, Año II, Nro. 332. Quito-Ecuador

Demirguc A, Klapper L. y Singer D., et. al. (2018). La base de datos Global Findex 2017: Medición de la inclusión financiera y la revolución de la tecnología financiera. Washington, DC: Banco Mundial. Recuperado de:

https://openknowledge.worldbank.org/bitstream/handle/10986/29510/211259ovSP.pdfg EIU (Economist Intelligence Unit), (2018); Microscopio Global 2018: El entorno para la Inclusión Financiera; Patrocinado por AfDB, Bill \& Melinda Gates Foundation, Accion, IDB/IDB Invest, Accion, and Metlife Foundation. EIU, Nueva York, NY. Recuperado de: http://www.findevgateway.org/sites/default/files/publication_files/es_microscopio_2018.pdf Instituto Nacional de Estadísticas y Censos-INEC. 2010, Censo poblacional 2010. Resultados Nacionales y provinciales, disponibles en. http://indestadistica.sni.gob.ec/QvAJAXZfc/opendoc.htm?document=SNI.qvw\&host=QV 
S@kukuri\&anonymous=truehttp://indestadistica.sni.gob.ec/QvAJAXZfc/opendoc.htm?do cument=SNI.qvw\&host=QVS @ kukuri\&anonymous=true\&bookmark=Document/BM40. http://www.ecuadorencifras.gob.ec/documentos/webinec/Bibliotecas/Fasciculos_Censales/Fasc_Cantonales/Los_Rios/Fasciculo_Quevedo.pdf

Tovar, P. (2017). Mecanismos de inclusión Financiera en Ecuador, Intendencia Nacional de Riesgos y Estudios, Superintendencia de Bancos del Ecuador, pp. 1-66. Recuperado el 10 de octubre de 2018 http://estadisticas.superbancos.gob.ec/portalestadistico/portalestudios/wpcontent/uploads/sites/4/downloads/2018/05/Inclusion_financiera_dic_17.pdf

Pérez E. \& Titelman D. 2018. (Editores), La inclusión financiera para la inserción productiva y el papel de la banca de desarrollo, Libros de la CEPAL, $\mathrm{N}^{\circ} 153$. (LC/PUB.2018/18-P), Santiago, Comisión Económica para América Latina y el Caribe (CEPAL), 2018.

Polan F. 2017. Estudio de Inclusión Financiera en el Ecuador: acceso y uso de Servicios Financieros, Unidad de Estadísticas. Red de Instituciones Financieras en Desarrollo (RFD), Quito Ecuador. Recuperado de: http://www.rfr.org.ec/index.php/comunicacion/2018-01-17-18-07-35.html

Purcachi W, Pérez M \& Arguello L. 2017. Análisis Del Proceso Innovador De Las Microempresas Del Área Urbana Del Cantón Quevedo, Ecuador. Revista ECA Sinergia. Facultad de Ciencias Administrativas y Económicas. UTM junio 2017 Vol. 8 №1. Recuperado de: http://oaji.net/articles/2017/5813-1516641497.pdf

Ramos, H. (2018). Inclusión Financiera aproximaciones teóricas y prácticas (libro). Banco Central del Ecuador. Quito Ecuador. Recuperado de: https://contenido.bce.fin.ec/documentos/PublicacionesNotas/Catalogo/Cuestiones/Inclusio n\%20Financiera.pdf 
Superintendencia de Bancos del Ecuador -SB. Distribución Geográfica de la Serie de Captaciones y Colocaciones Bancos privados y públicos. Reportes Gerenciales. Boletines mensuales. Dirección de Estudios y Gestión de la Información -DEGI. Recuperado de: https://estadisticas.superbancos.gob.ec/portalestadistico/portalestudios/

Superintendencia de Economía Popular y Solidaria -SEPS. Boletines Financieros, Captaciones y Colocaciones del Sector Financiero Popular y Solidario, Dirección Nacional Técnica y Estadística-DNTE. Sistema de Acopio Integral Recuperado de: http://www.seps.gob.ec/estadisticas?productos-estadisticos.

\section{Anexos}

Anexol.

Cartera Bruta por tipo de crédito del Sector Financiero popular y Solidario con presencia en el Cantón Quevedo, a diciembre 2018. en dólares y porcentajes.

\begin{tabular}{|c|c|c|c|c|c|c|c|c|}
\hline SFPS & & $\begin{array}{l}\text { OMERCIAL } \\
\text { RIORITARIO } \\
\text { PYMES }\end{array}$ & & $\begin{array}{l}\text { CONSUMO } \\
\text { PRIORITARIO }\end{array}$ & MICROCREDITO & INMOBILIARIO & TOTAL & \% PART. \\
\hline COAC POLICIA NACIONAL & $\$$ & $130,138.69$ & $\$$ & $69,616,326.61$ & $\$ 3,660,016.31$ & $2,510,305.62$ & $75,786,648.54$ & $69.11 \%$ \\
\hline COAC CACPECO & $\$$ & $628,836.78$ & $\$$ & $1,743,616.35$ & $\$ 11,999,293.96$ & $62,350.89$ & $13,805,261.20$ & $12.59 \%$ \\
\hline MUTUALISTA PICHINCHA & $\$$ & $262,587.21$ & $\$$ & $1,728,486.23$ & & $8,873,398.43$ & $\$ 10,601,884.66$ & $9.67 \%$ \\
\hline COAC 29 DE OCTUBRE LTDA & & & $\$$ & $2,809,738.19$ & $\$ 2,884,440.68$ & $35,041.05$ & $\$ \quad 5,729,219.92$ & $5.22 \%$ \\
\hline COAC JUAN PIO DE MORA & & & $\$$ & $380,601.18$ & $568,186.30$ & $78,280.68$ & $1,027,068.16$ & $0.94 \%$ \\
\hline COAC SAN ANTONIO & & & $\$$ & $200,761.85$ & $653,113.25$ & $23,510.89$ & $877,385.99$ & $0.80 \%$ \\
\hline COAC JEP & & & $\$$ & $370,291.30$ & $446,873.25$ & & $817,164.55$ & $0.75 \%$ \\
\hline TOTAL SFPS & & $1,021,562.68$ & $\$$ & $76,849,821.71$ & $\$ 20,211,923.75$ & $\$ 11,582,887.56$ & $\$ 109,666,195.70$ & $53 \%$ \\
\hline \% DE PARTICIPACIÓN SFPS & & $1 \%$ & & $70 \%$ & $18 \%$ & $11 \%$ & $100 \%$ & \\
\hline
\end{tabular}

Fuente: Dirección Nacional Técnica y Estadística. Reportes de colocaciones. DIEE-SEPS. Elaboración: Autoras

Anexo2.

Cartera Bruta por tipo de crédito del Sector Financiero popular y Solidario con presencia en el Cantón Quevedo, a diciembre 2018. en dólares y porcentajes. 
Vergara, L., Véliz, M. y Culcay, M.

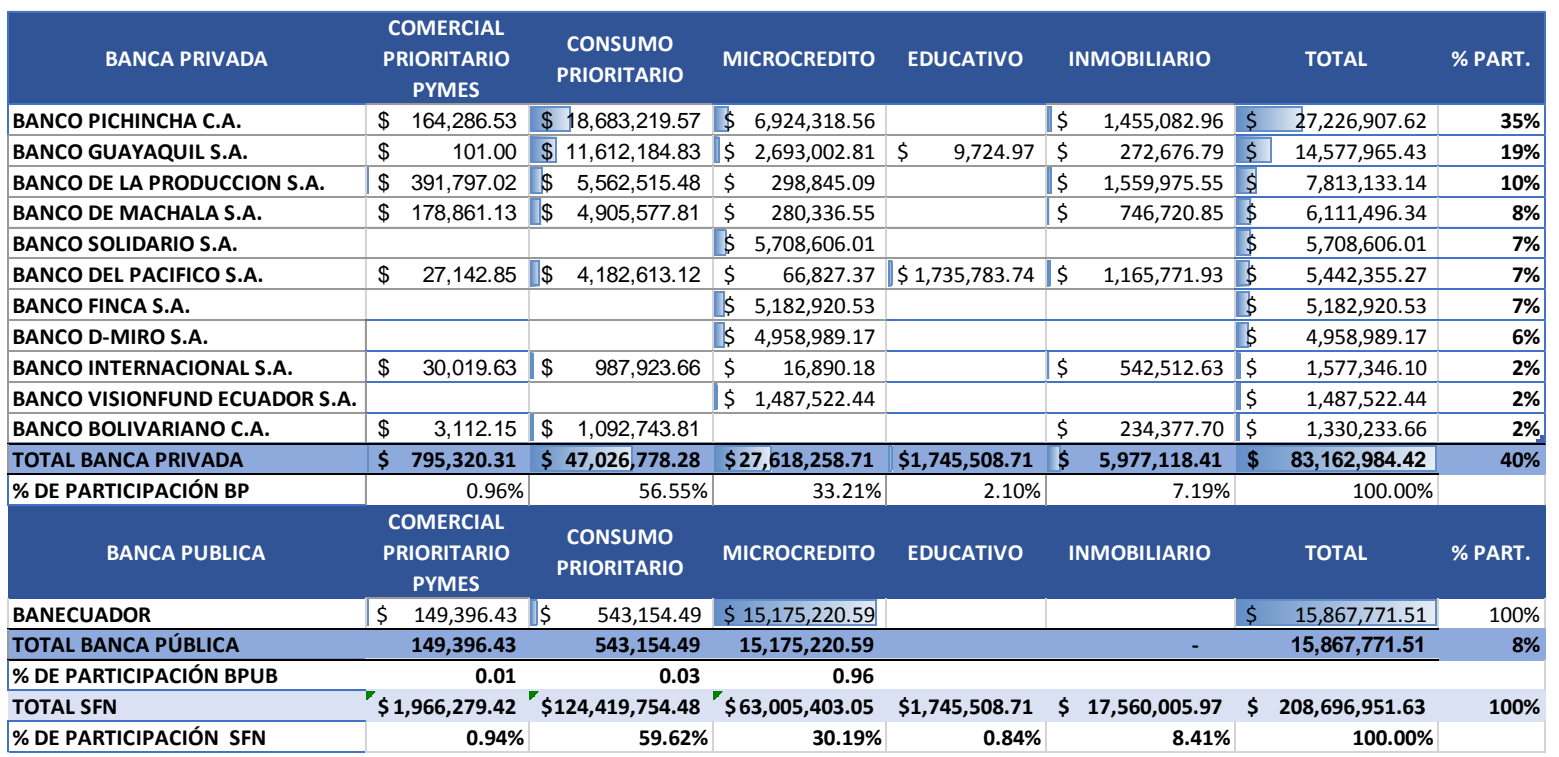

Fuente: Distribución Geográfica de la Serie de Colocaciones. BP-BPU-SB. Elaboración: Autoras

Anexo3.

Volumen del número de operaciones por tipo de crédito del Sector Financiero popular y Solidario con presencia en el Cantón Quevedo, a diciembre 2018. en unidades y porcentajes.

\begin{tabular}{|c|c|c|c|c|c|c|}
\hline SFPS & $\begin{array}{l}\text { COMERCIAL } \\
\text { PRIORITARIO } \\
\text { PYMES }\end{array}$ & $\begin{array}{l}\text { CONSUMO } \\
\text { PRIORITARIO }\end{array}$ & MICROCREDITO & INMOBILIARIO & TOTAL & \% PART. \\
\hline COAC POLICIA NACIONAL & 38 & 54,644 & 945 & 47 & 55,636 & $84.22 \%$ \\
\hline COAC CACPECO & 185 & 1,369 & 3,099 & 1 & 4,468 & $6.76 \%$ \\
\hline MUTUALISTA PICHINCHA & 77 & 1,357 & & $165^{\top}$ & 1,600 & $2.42 \%$ \\
\hline COAC 29 DE OCTUBRE LTDA & & 2,205 & 745 & 1 & 2,951 & $4.47 \%$ \\
\hline COAC JUAN PIO DE MORA & & 299 & 147 & 1 & 447 & $0.68 \%$ \\
\hline COAC SAN ANTONIO & & 158 & 169 & & 326 & $0.49 \%$ \\
\hline COAC JEP & & 291 & 115 & & 291 & $0.44 \%$ \\
\hline TOTAL SFPS & 301 & 60,322 & 5,219 & 216 & 66,057 & $57.38 \%$ \\
\hline \% DE PARTICIPACIÓN & $0.5 \%$ & $91.3 \%$ & $7.9 \%$ & $0.3 \%$ & $100.0 \%$ & \\
\hline
\end{tabular}

Fuente: Dirección Nacional de Síntesis Macroeconómica (BCE) Se calculó relacionando el monto de cartera colocada para el monto promedio de crédito ultimo disponible a la fecha de elaboración de la investigación: Evolución de las Operaciones Activas y Pasivas del Sistema Financiero Nacional del BCE a febrero de 2018., Comercial (3.394), Consumo (1.274), Microempresarial (3872.6), Educativo (10801.12), Vivienda (53632.9). Elaboración: Autoras

\section{Anexo 4.}

Volumen del número de operaciones por tipo de crédito del Sector Financiero Público y Privado con presencia en el Cantón Quevedo, a noviembre 2018. en unidades y porcentajes. 
Revista Ciencias Sociales y Económicas - UTEQ (2019)

ISSN 2588-0586 IMPRESO; ISSN 2588-0594 ELECTRÓNICO

Volumen 3, Número 1. Semestral (enero-junio)

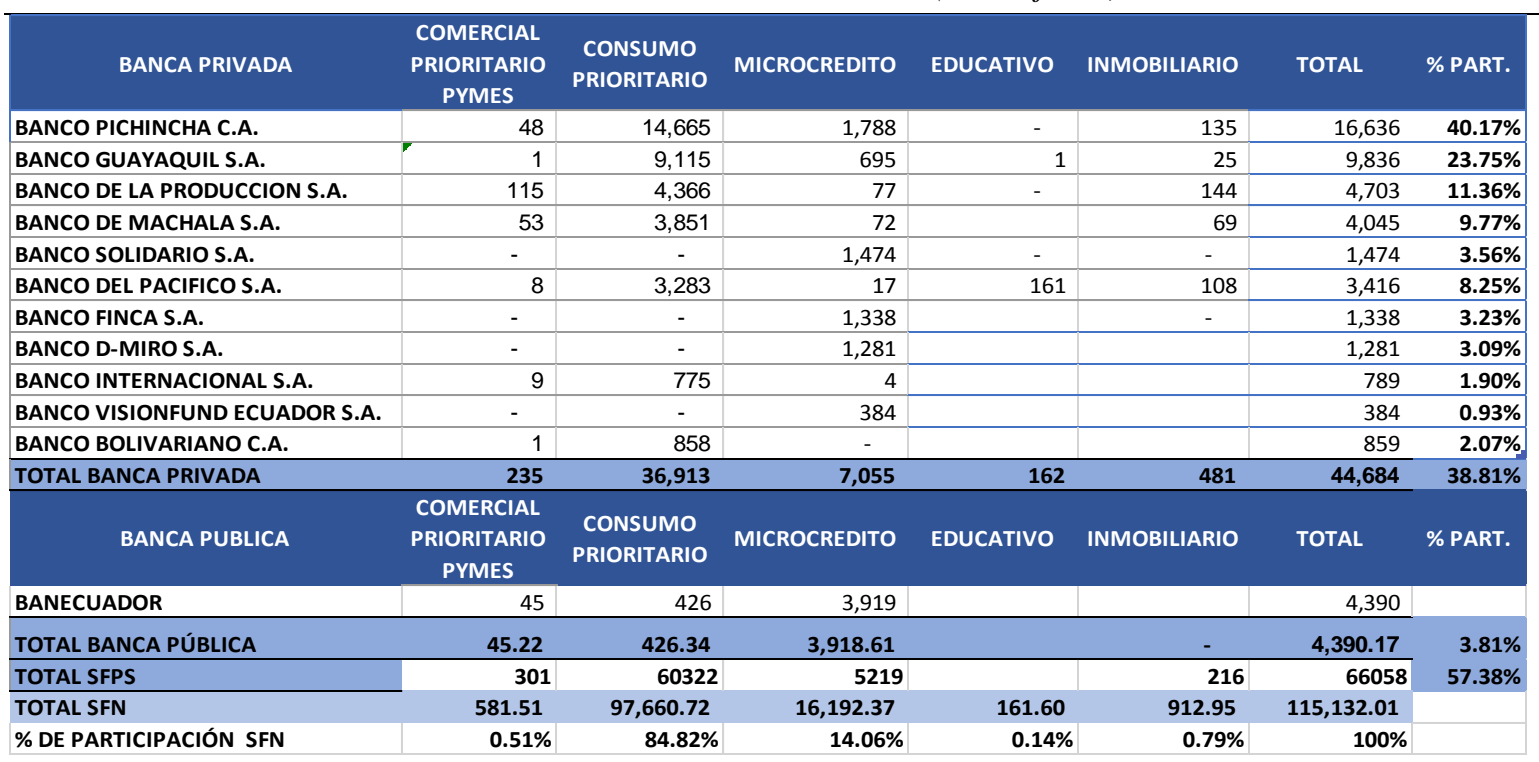

Fuente: Dirección Nacional de Síntesis Macroeconómica (BCE). Elaboración: Autoras

\section{Anexo 5.}

Cartera por tipo de Depósito, Número de Cuentas y Clientes, y Monto Promedio en Cuentas del Sistema Financiero Nacional con presencia en el Cantón Quevedo, a diciembre 2018 (SFPS). a noviembre 2018 (BPBPU) en dólares, unidades y porcentajes.

\begin{tabular}{|c|c|c|c|c|c|c|c|c|c|c|}
\hline SFPS & & positos a la vista & $\begin{array}{c}\text { Depositos a } \\
\text { plazo }\end{array}$ & & $\begin{array}{l}\text { Depositos } \\
\text { restringidos }\end{array}$ & & TOTAL & CLIENTES & CUENTAS & $\begin{array}{c}\text { MONTO } \\
\text { PROMEDIO } \\
\text { EN CUENTAS }\end{array}$ \\
\hline MUTUALISTA PICHINCHA & $\$$ & $5,696,877.44$ & $\$ 7,519,457.07$ & $\$$ & $263,096.94$ & $\$$ & $13,479,431.45$ & 9,691 & 10,089 & $\$ \quad 564.66$ \\
\hline COAC 29 DE OCTUBRE LTDA & $\$$ & $3,823,076.06$ & $\$ 5,003,571.77$ & $\$$ & $1,966.54$ & $\$$ & $8,828,614.37$ & 15370 & 15863 & 241.01 \\
\hline COAC CACPECO & $\$$ & $4,717,872.11$ & $\$ 3,339,354.16$ & $\$$ & $662,075.85$ & $\$$ & $8,719,302.12$ & 178272 & 19145 & 246.43 \\
\hline COAC JUAN PIO DE MORA & $\$$ & $83,894.18$ & $\$ \quad 444,806.79$ & $\$$ & $48,335.34$ & $\$$ & $577,036.31$ & 2658 & 2870 & 29.23 \\
\hline COAC SAN ANTONIO & $\$$ & $327,432.56$ & $212,521.52$ & & & $\$$ & $539,954.08$ & 2021 & 3157 & 103.72 \\
\hline BANCA PRIVADA & & positos a la vista & $\begin{array}{c}\text { Depositos a } \\
\text { plazo }\end{array}$ & & $\begin{array}{l}\text { Depositos } \\
\text { restringidos }\end{array}$ & & TOTAL & CLIENTES & CUENTAS & $\begin{array}{c}\text { MONTO } \\
\text { PROMEDIO } \\
\text { EN CUENTAS }\end{array}$ \\
\hline BANCO PICHINCHA C.A. & $\$$ & $55,683,515.84$ & $\$ 16,003,371.36$ & $\$$ & $1,542,748.43$ & & 73229635.63 & 66,149 & 77326 & $\$ \quad 720.11$ \\
\hline BANCO DE MACHALA S.A. & $\$$ & $15,163,978.17$ & $\$ 16,148,050.04$ & $\$$ & $889,665.74$ & & 32201693.95 & 9316 & 9433 & $1,607.55$ \\
\hline BANCO INTERNACIONAL S.A. & $\$$ & $11,597,869.90$ & $\$ 6,798,421.29$ & $\$$ & $291,715.40$ & & 18688006.59 & 8335 & 8599 & $1,348.75$ \\
\hline BANCO FINCA S.A. & $\$$ & $409,163.48$ & $\$ \quad 654,954.90$ & & & & 1064118.38 & 5981 & 12052 & 33.95 \\
\hline BANCO D-MIRO S.A. & $\$$ & $239,306.85$ & $\$ \quad 272,019.78$ & & & & 511326.63 & 5556 & 5580 & 42.89 \\
\hline TOTAL BANCA PRIVADA & $\$$ & $123,911,771.77$ & $\$ 51,497,192.56$ & $\$$ & $5,233,268.22$ & $\$$ & $180,642,232.55$ & 160,584 & 179805 & 818.41 \\
\hline \% DE PARTICIPACIÓN & & $68.60 \%$ & $28.51 \%$ & & $2.90 \%$ & & $100.00 \%$ & $38 \%$ & $62 \%$ & $191 \%$ \\
\hline BANCA PUBLICA & & positos a la vista & $\begin{array}{c}\text { Depositos a } \\
\text { plazo }\end{array}$ & & $\begin{array}{l}\text { Depositos } \\
\text { restringidos }\end{array}$ & & TOTAL & CLIENTES & CUENTAS & $\begin{array}{c}\text { MONTO } \\
\text { PROMEDIO } \\
\text { EN CUENTAS }\end{array}$ \\
\hline BANECUADOR & & 9455204.16 & 4928988.95 & & 20706.5 & & 14404899.61 & 53292 & 53586 & $\$ \quad 176.45$ \\
\hline TOTAL BANCA PÚBLICA & & $9,455,204.16$ & $4,928,988.95$ & & $20,706.50$ & & $14,404,899.61$ & 53,292 & 53,586 & 176.45 \\
\hline \% DE PARTICIPACIÓN & & $66 \%$ & $34 \%$ & & $0 \%$ & & $100 \%$ & $13 \%$ & $18 \%$ & $41 \%$ \\
\hline TOTAL SFN & $\$$ & $151,321,309.04$ & $\$ 80,444,656.95$ & & $6,229,449.39$ & $\$$ & $237,995,415.38$ & $425,852.00$ & $290,488.00$ & 428.20 \\
\hline
\end{tabular}

Fuente: Reportes de Captaciones. DIEE-SEPS y Distribución Geográfica de la Serie de Captaciones. BP-BPUSB. Elaboración: Autoras 